\title{
NÚMERO DE CASOS CONFIRMADOS DE HEPATITIS VIRAL EN BRASIL ENTRE 2010 Y 2015
}

\section{ARTÍCULO ORIGINAL}

NUNES, Filipe Sales', FACCO, Lucas², FECURY, Amanda Alves³, ARAÚJO, Maria Helena Mendonça de ${ }^{4}$, OLIVEIRA, Euzébio de ${ }^{5}$, DENDASCK, Carla Viana ${ }^{6}$, SOUZA, Keulle Oliveira da ${ }^{7}$, DIAS, Claudio Alberto Gellis de Mattos ${ }^{8}$

NUNES, Filipe Sales. Et al. Número de casos confirmados de hepatitis viral en Brasil entre 2010 y 2015. Revista Científica Multidisciplinar Núcleo do Conhecimento. Año 05, Ed. 11, Vol. 25, págs. 71 a 80. Noviembre de 2020. ISSN: 2448-0959, Link de acesso:

https://www.nucleodoconhecimento.com.br/salud/hepatitis-viral, DOI: 10.32749/nucleodoconhecimento.com.br/salud/hepatitis-viral

\section{RESUMEN}

La hepatitis viral son enfermedades infecciosas que atacan el hígado, y sus agentes causales son virus. Este estudio tiene como objetivo demostrar el número de casos confirmados de hepatitis viral en Brasil entre 2010 y 2015. Se realizó una búsqueda en la base de datos DATASUS en el sitio web (http://datasus.saude.gov.br/). La hepatitis representa un gran problema de salud pública en Brasil. De los infectados, una gran parte está compuesta por individuos varones, y la demanda más baja

\footnotetext{
${ }^{1}$ Técnico de Redes Informáticas, graduado del Instituto Federal de Amapá (IFAP).

${ }^{2}$ Estudiante del Curso de Medicina de la Universidad Federal de Amapá (UNIFAP).

${ }^{3}$ Biomédica, Doctora en Enfermedades Tropicales, Profesora e investigadora del Curso Médico de la Universidad Federal de Amapá (UNIFAP).

${ }^{4}$ Médico, Profesor e investigador del Curso Médico de la Universidad Federal de Amapá (UNIFAP).

${ }^{5}$ Biólogo, Doctor en Enfermedades tópicas, Profesor e investigador del Curso de Educación Física de la Universidad Federal de Pará (UFPA).

${ }^{6}$ Teólogo, Doctor en Psicoanálisis, investigador del Centro de Investigación y Estudios Avanzados - CEPA.

${ }^{7}$ Sociólogo, Máster en Estudios Antrópicos en la Amazonía, Miembro del Grupo de Investigación "Laboratorio de Educación, Medio Ambiente y Salud" (LEMAS/UFPA).

${ }^{8}$ Biólogo, Doctor en Teoría e Investigación del Comportamiento, Profesor e investigador del Programa de Posgrado en Educación Profesional y Tecnológica (PROFEPT), Instituto Federal de Amapá (IFAP).
}

RC: 67622

Disponible: https://www.nucleodoconhecimento.com.br/salud/hepatitis-viral 
visible de servicios de salud es un factor importante para este hallazgo. La hepatitis B y C son las más comunes entre las hepatitis virales y uno de los factores importantes y que contribuyen a la tasa de hepatitis infectada es su coinfección con el $\mathrm{VIH}$. Se deben realizar pruebas de laboratorio (inmunoensayo, pruebas moleculares) para detectar marcadores y determinar el agente etiológico causante de la patología.

Palabras clave: Epidemiología, virus, hepatitis.

\section{INTRODUCCIÓN}

La hepatitis viral son enfermedades infecciosas que atacan el hígado. Se consideran un problema de salud pública en Brasil debido a su gran número de casos confirmados (MARGREITER et al., 2015; LEITE, et al., 2020).

Los agentes etiológicos descubiertos de la hepatitis viral son los virus VPH, VHB, VHV, VHD y VHE, que tienen en común la facilidad de unión con las células hepáticas. Presentan diferencias en su forma clínica y características epidemiológicas (NUNES et al., 2016).

La hepatitis $\mathrm{A}(\mathrm{VHA})$ y la $\mathrm{E}(\mathrm{VHE})$ tienen sus virus transmitidos por la vía fecal-oral, y se pueden encontrar en agua y alimentos contaminados. La falta de un tratamiento adecuado del agua consumida y el manejo inadecuado de los alimentos son los principales factores de la propagación del virus. La enfermedad, al presentar síntomas, puede causar una disminución en el apetito, fiebre y cambios en el color de la orina del individuo infectado (MOCBEL et al., 2016).

El virus de la hepatitis A tiene una vacuna eficaz, considerada segura, y puede mantener una inmunidad de varios de 5 a 10 años. La vacuna se divide en dos dosis y se puede aplicar a niños a partir del primer año de edad (FERREIRA et al., 2014). La hepatitis E tiene una vacuna, pero no a escala mundial. Inicialmente

RC: 67622

Disponible: https://www.nucleodoconhecimento.com.br/salud/hepatitis-viral 
comercializado en 2012 y producido en China, ya se considera eficaz (NUNES et al., 2016).

El virus de la hepatitis $\mathrm{C}(\mathrm{VHC})$ se transmite principalmente por transfusión de sangre, y también por relaciones sexuales, forma congénita y uso compartido de objetos afilados o higiene personal. La hepatitis $C$ tiene un diagnóstico más complicado debido a la complejidad de su virus. En menos de la mitad de los casos no es posible identificar la fuente mecánica de la infección. La mayoría de los casos de hepatitis $C$ alcanzan la forma crónica sin presentar síntomas. Por lo general, se manifiestan sólo después de años de infección cuando los individuos se encuentran en una etapa más grave. La minoría de casos generalmente progresan a cirrosis hepática o cáncer de hígado (GUSMÃO et al., 2017).

El tratamiento varía según el genotipo del virus, utilizando medicamentos para prevenir la reproducción del virus, reduciendo así el empeoramiento de la infección. La duración del tratamiento puede ser de 48 a 72 semanas, donde puede haber una gran disminución en la carga viral en el paciente, pero no una extinción total del virus (SILVA et al., 2014). Aún no se ha desarrollado una vacuna contra el virus de la hepatitis C. Una de las formas de prevenir la propagación del virus es la movilización de grupos de riesgo, como los consumidores de drogas y los profesionales de la salud (GUSMÃO et al., 2017).

La hepatitis $\mathrm{B}(\mathrm{VHB})$ tiene su virus transmitido verticalmente, transmitido de madre a hijo en el momento del parto o por lactancia materna. También compartiendo objetos afilados como agujas y alicates, transfusión de sangre y forma sexual (FRANCISCO et al., 2015).

La hepatitis B y D puede presentarse en dos formas clínicas: aguda y crónica. Cuando presentan síntomas, son idénticos, como malestar físico; cambios en la tinción de orina; heces; coloración amarillenta de la piel y los ojos (BRASIL, 2014; BRASIL, 2014a).

RC: 67622

Disponible: https://www.nucleodoconhecimento.com.br/salud/hepatitis-viral 
El virus de la hepatitis $D(V H D)$ requiere directamente que el virus de la hepatitis $B$ (VHB) sea infeccioso, por lo que los medios de transmisión son los mismos, ya que no es posible que un individuo se infecte con el VHB sin VHB. La vacuna contra el virus de la hepatitis $B$ también es eficaz para la inmunización contra la hepatitis $D$ debido a la relación de infección por virus articulares (NUNES et al., 2016).

\section{OBJETIVO}

Demostrar el número de casos confirmados de hepatitis viral en Brasil entre 2010 y 2015.

\section{MÉTODO}

Se realizó una búsqueda en la base de datos DATASUS en el sitio web (http://datasus.saude.gov.br/), desde donde se eliminaron los datos, siguiendo los pasos: En el menú del sitio elegimos la pestaña "Acceso a la información" y luego la opción "INFORMACIÓN DE SALUD TABNET", luego la opción "Epidemiologías y morbilidad". Después de cargar la página, se seleccionó el grupo "Enfermedades y enfermedades de notificación- A partir de 2007 (SINAN)" y se seleccionó la opción "Hepatitis" y en la pestaña "Cobertura geográfica" se seleccionó la opción "Brasil por región, UF y municipio".En la opción de columna seleccionada, "No activo", "Género", "Grupo de edad", "Clase. Etiological", "Source Mecan Infection", "Class. Final", "Forma Clínica", "Escuela". Para cada elemento seleccionado en la columna, en la línea siempre "Year Diag/symptoms", y en el Período siempre se utilizaron los años 2010 a 2015. Los datos se compilaron dentro de la aplicación Excel, un componente de la suite de Microsoft Corporation Office. La investigación bibliográfica se llevó a cabo en artículos científicos, utilizando computadoras del laboratorio de computación del Instituto Federal de Educación, Ciencia y Tecnología de Amapá, Campus Macapá, ubicado en: Rodovia BR 210 KM 3, s/n - Bairro Brasil Novo. CEP: 68.909-398, Macapá, Amapá, Brasil.

RC: 67622

Disponible: https://www.nucleodoconhecimento.com.br/salud/hepatitis-viral 


\section{RESULTADOS}

La Figura 1 muestra el número de casos confirmados de hepatitis viral en Brasil entre 2010 y 2015 . Entre 2010 y 2013, los datos muestran un aumento en el número de casos. Entre 2013 y 2015 hay una disminución en las infecciones virales por hepatitis.

Figura 1 Número de casos confirmados de hepatitis viral en Brasil entre 2010 y 2015.

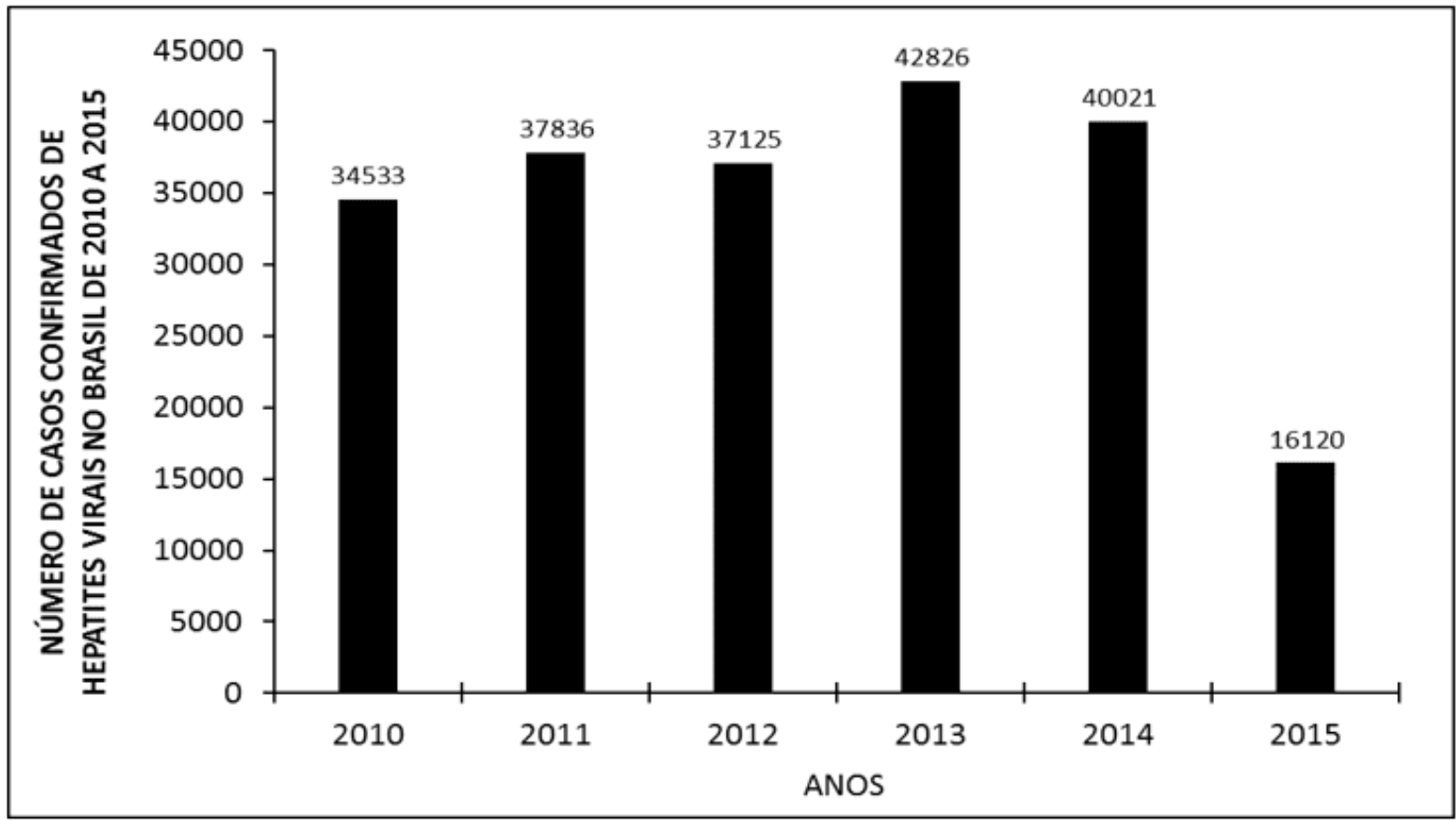

RC: 67622

Disponible: https://www.nucleodoconhecimento.com.br/salud/hepatitis-viral 
La Figura 2 muestra el número de casos confirmados de hepatitis viral en Brasil entre 2010 y 2015 por género. Los datos muestran un mayor número de casos entre los hombres en comparación con las hembras.

Figura 2 Número de casos confirmados de hepatitis viral en Brasil entre 2010 y 2015 por sexo.

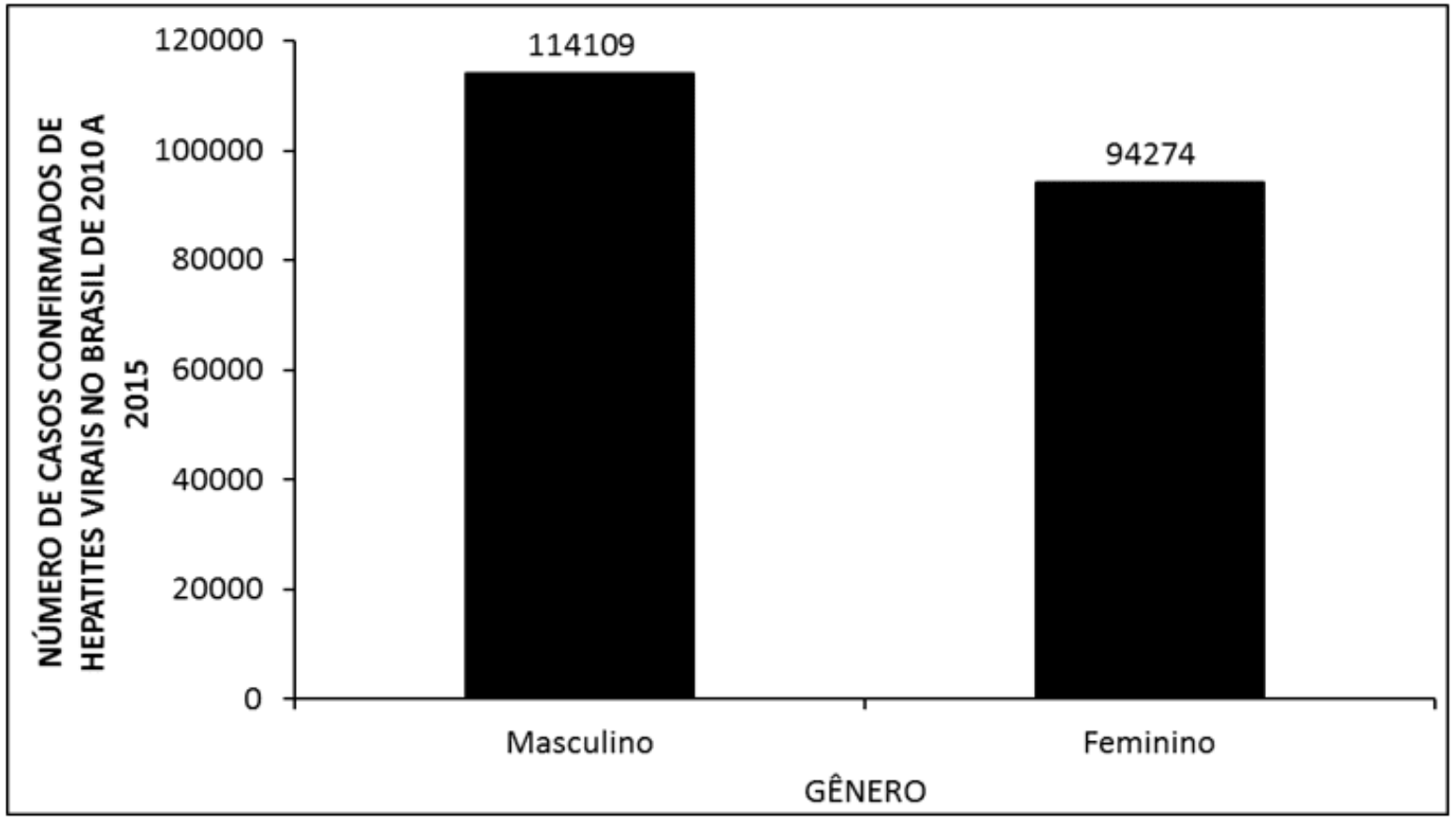

La Figura 3 muestra el número de casos confirmados de hepatitis viral en Brasil entre 2010 y 2015 por grupo de edad. El mayor número de casos ocurre en el grupo de edad entre 40 y 59 años, y el segundo mayor número entre 20 y 39 años.

RC: 67622

Disponible: https://www.nucleodoconhecimento.com.br/salud/hepatitis-viral 
Figura 3 Número de casos confirmados de hepatitis viral en Brasil entre 2010 y 2015 por grupo de edad

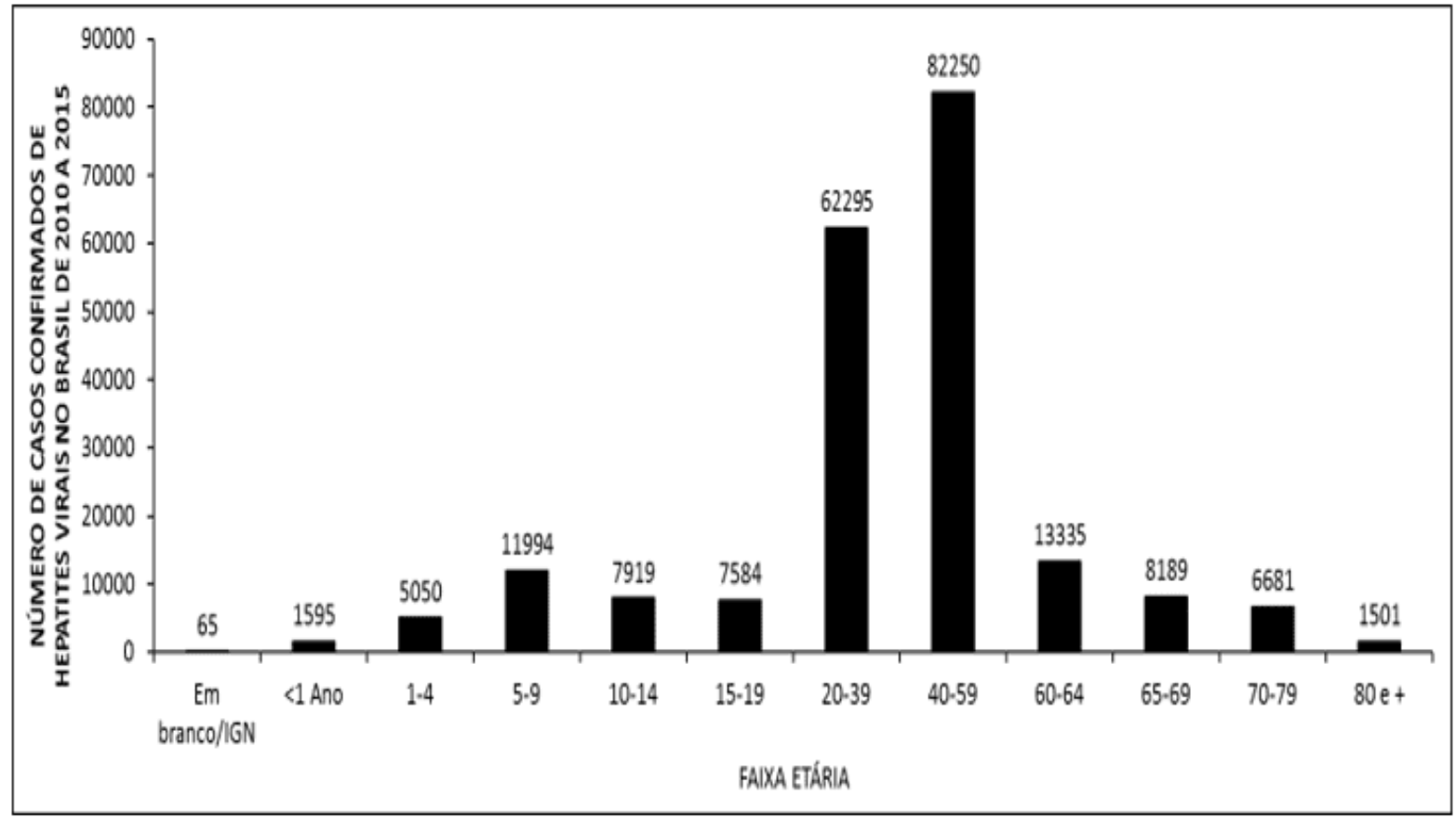

La Figura 4 muestra el número de casos confirmados de hepatitis viral en Brasil entre 2010 y 2015 por clase etiológica, la tasa más alta de la enfermedad que ocurre con la presentación del virus $\mathrm{C}$ el segundo más grande con el virus $\mathrm{B}$.

RC: 67622

Disponible: https://www.nucleodoconhecimento.com.br/salud/hepatitis-viral 
Figura 4 Número de casos confirmados de hepatitis viral en Brasil de 2010 a 2015 por clase etiológica.

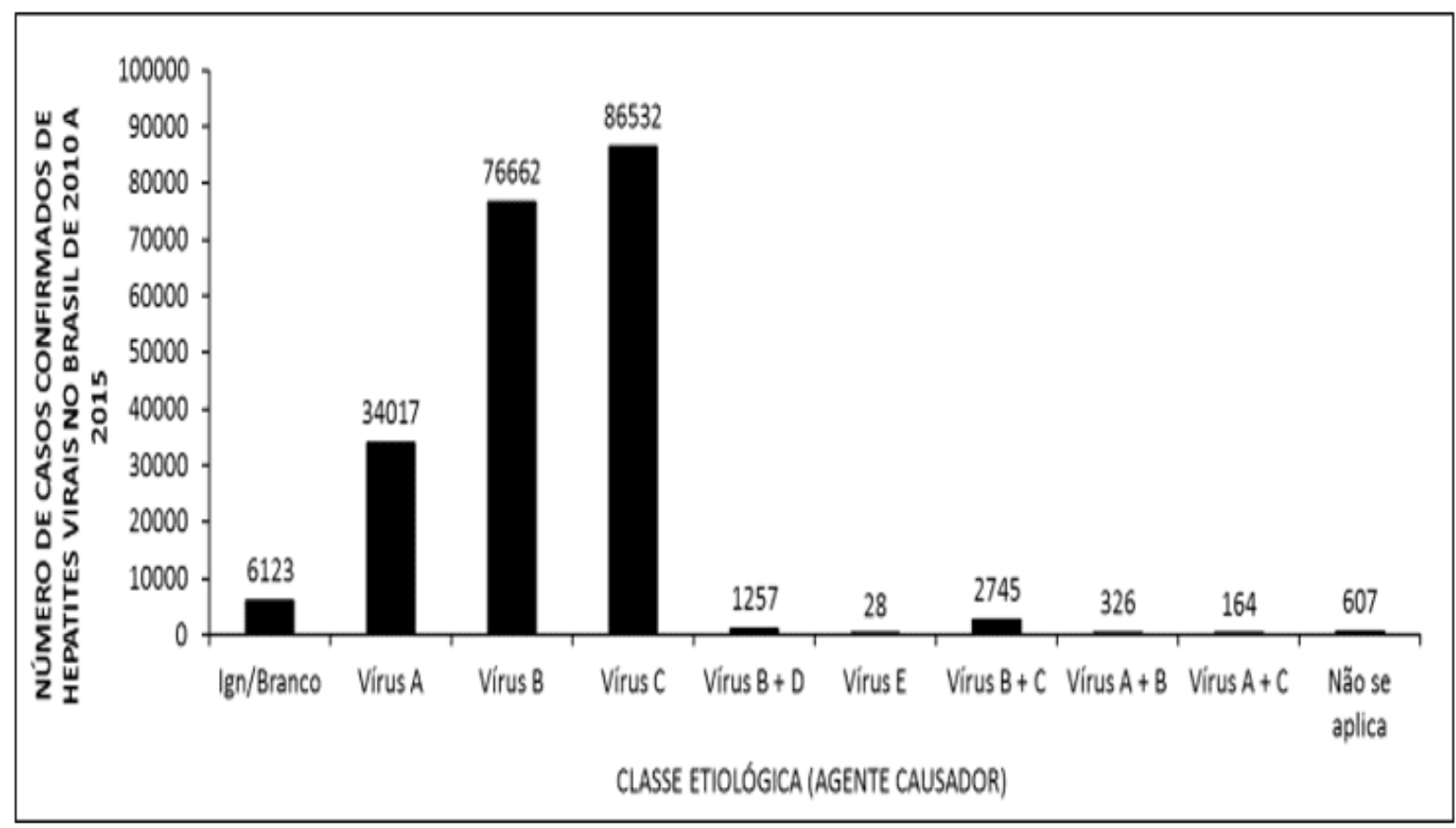

La Figura 5 muestra el número de casos confirmados de hepatitis viral en Brasil entre 2010 y 2015 por fuente mecánica de contaminación, lo que demuestra que el mayor número de casos, donde se reconoce la fuente mecánica, fue por transmisión sexual y segundo por Alimentos/Agua.

RC: 67622

Disponible: https://www.nucleodoconhecimento.com.br/salud/hepatitis-viral 
Figura 5 Gráfico con el número de casos confirmados de hepatitis viral en Brasil de 2010 a 2015 por fuente mecánica.

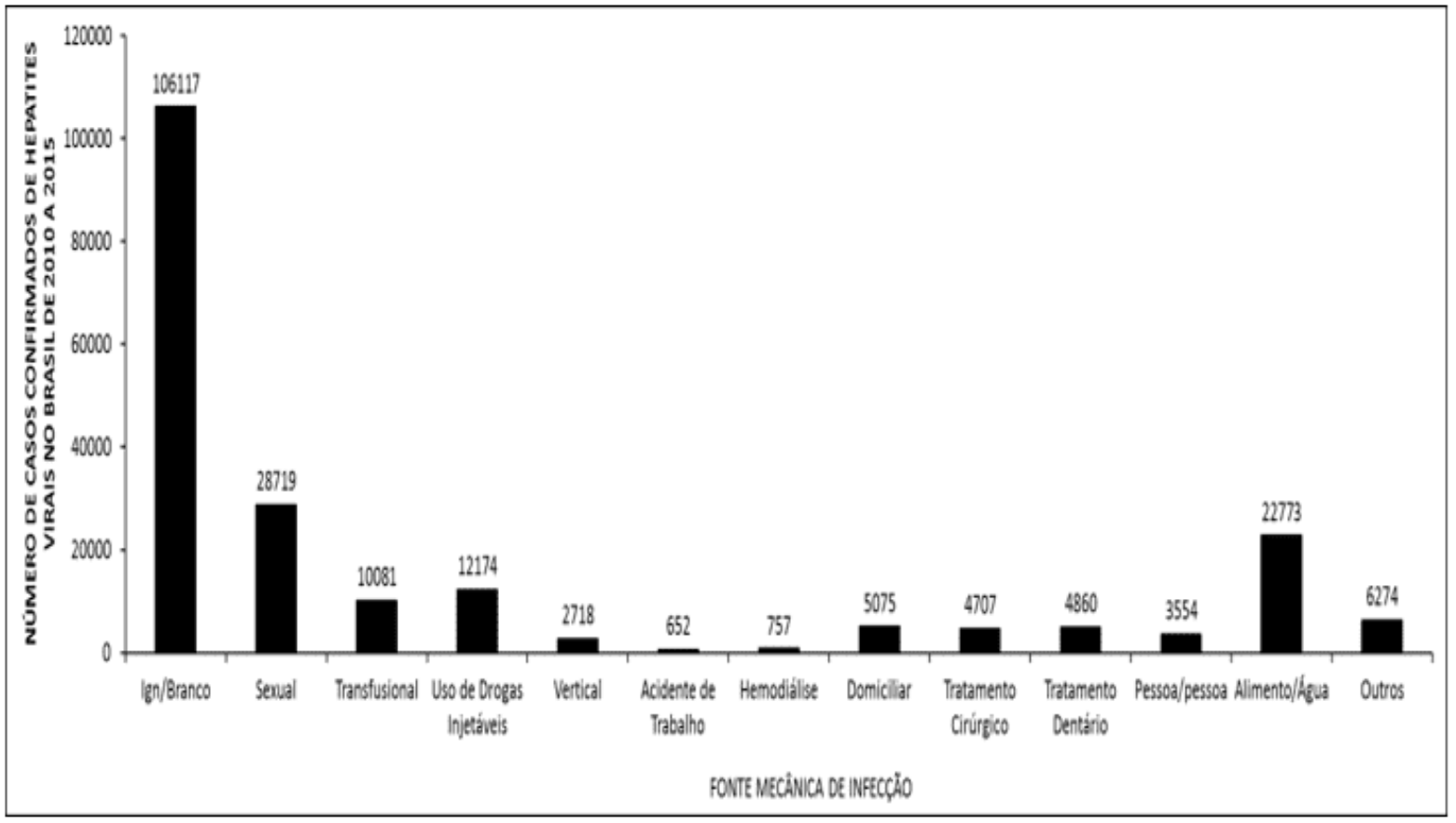

La Figura 6 muestra el porcentaje de casos confirmados de hepatitis viral en Brasil entre 2010 y 2015 por su clasificación final. Se registró que el mayor porcentaje de diagnósticos se realizó de manera laboratorio.

RC: 67622

Disponible: https://www.nucleodoconhecimento.com.br/salud/hepatitis-viral 
Figura 6 Gráfico con porcentaje de casos confirmados de hepatitis viral en Brasil por clasificación final entre 2010 y 2015.

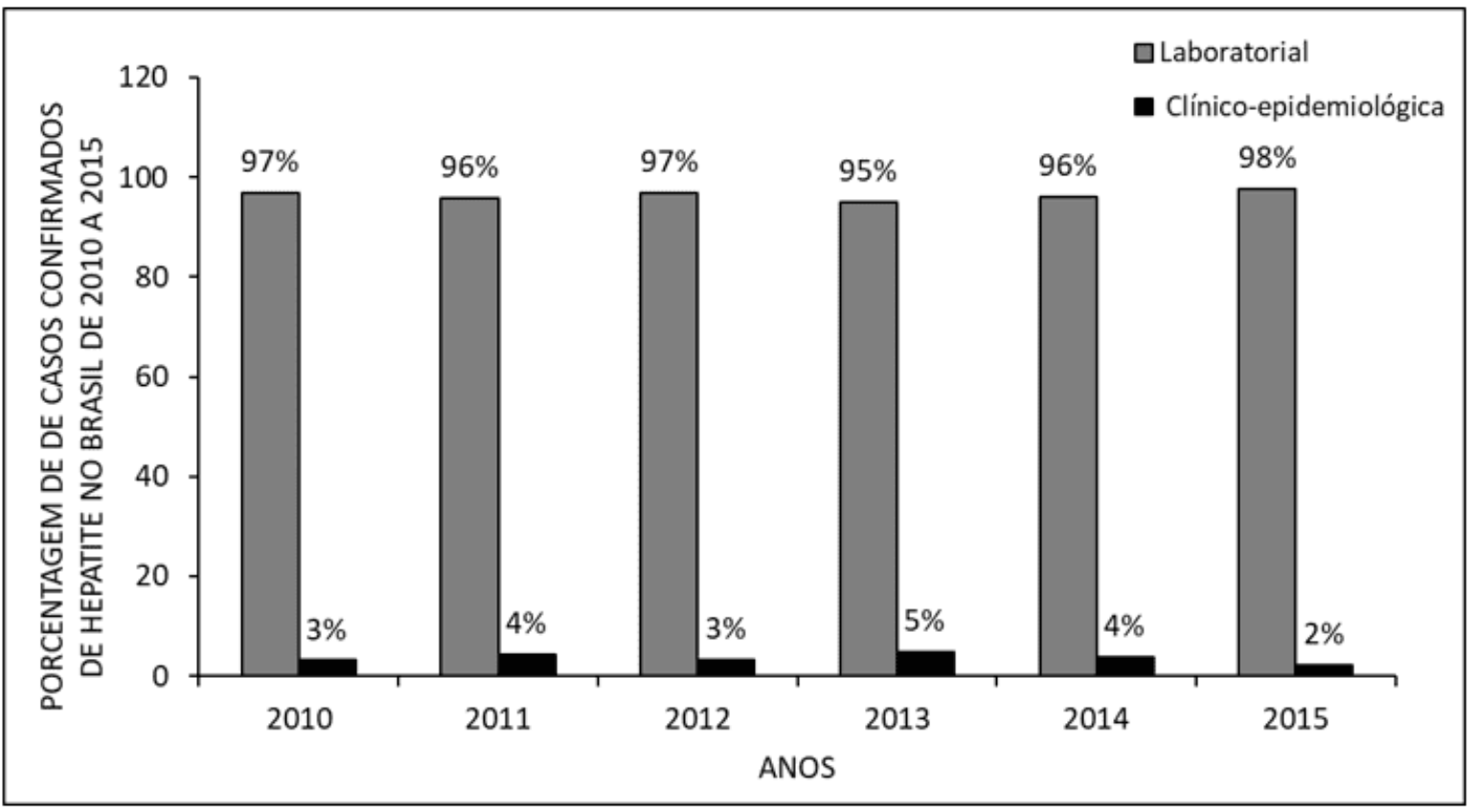

La Figura 7 muestra el número de casos confirmados de hepatitis viral en Brasil por forma clínica entre 2010 y 2015, lo que demuestra que la mayor incidencia es en forma de hepatitis/portadora crónica.

RC: 67622

Disponible: https://www.nucleodoconhecimento.com.br/salud/hepatitis-viral 
Figura 7 Número de casos confirmados de hepatitis viral en Brasil de 2010 a 2015 por forma clínica

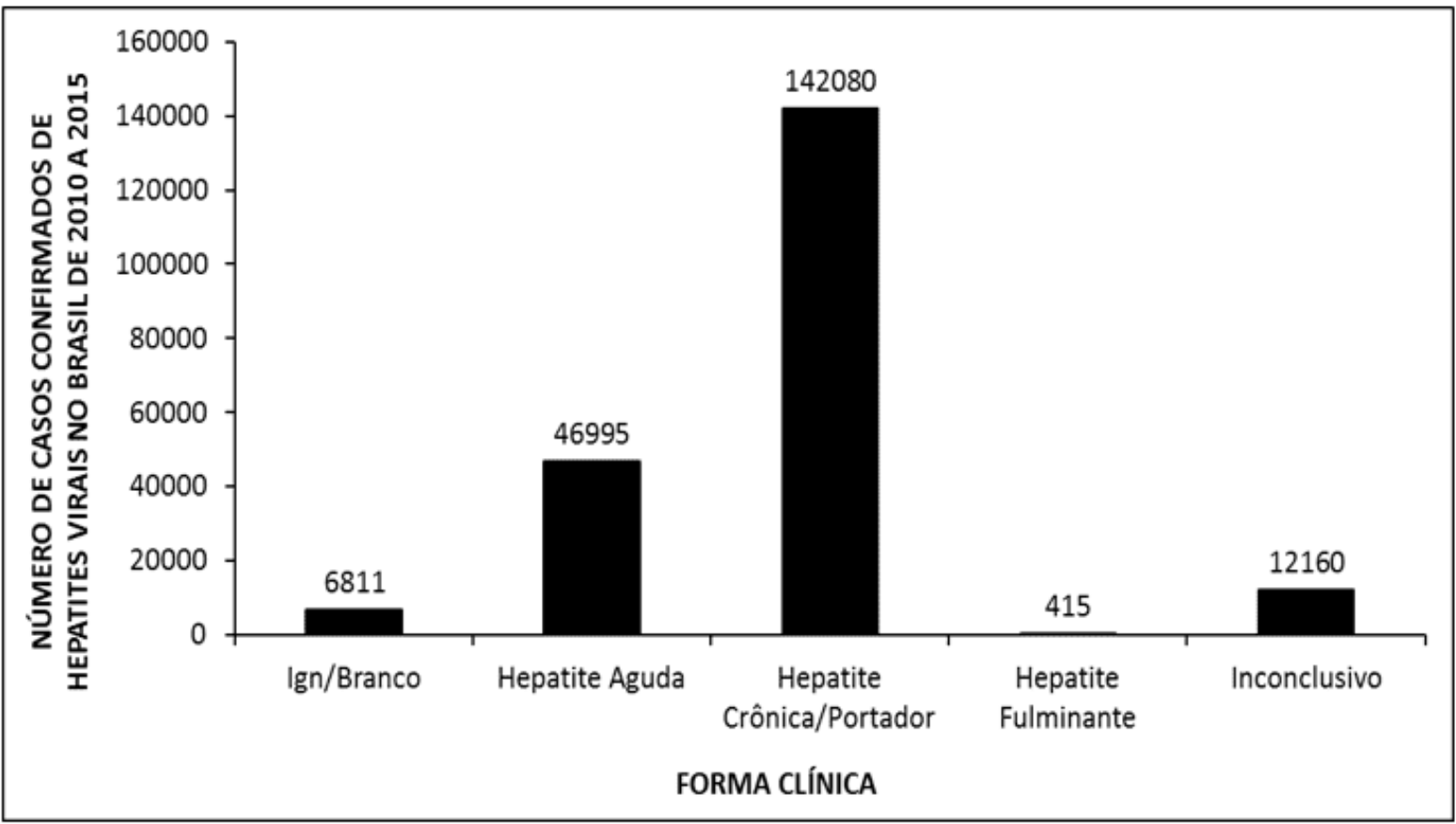

La Figura 8 muestra el número de casos confirmados de hepatitis viral en Brasil entre 2010 y 2015 según el nivel de educación de las personas infectadas. Demostrando que la mayor cantidad de casos, cuando el individuo identifica su educación, se da en personas con bachillerato completo y, en segundo lugar, con el 5a a $8^{\circ}$ grado incompleto de Educación Física.

RC: 67622

Disponible: https://www.nucleodoconhecimento.com.br/salud/hepatitis-viral 
Figura 8 Número de casos confirmados de hepatitis viral en Brasil entre 2010 y 2015 por escolarización de individuos.

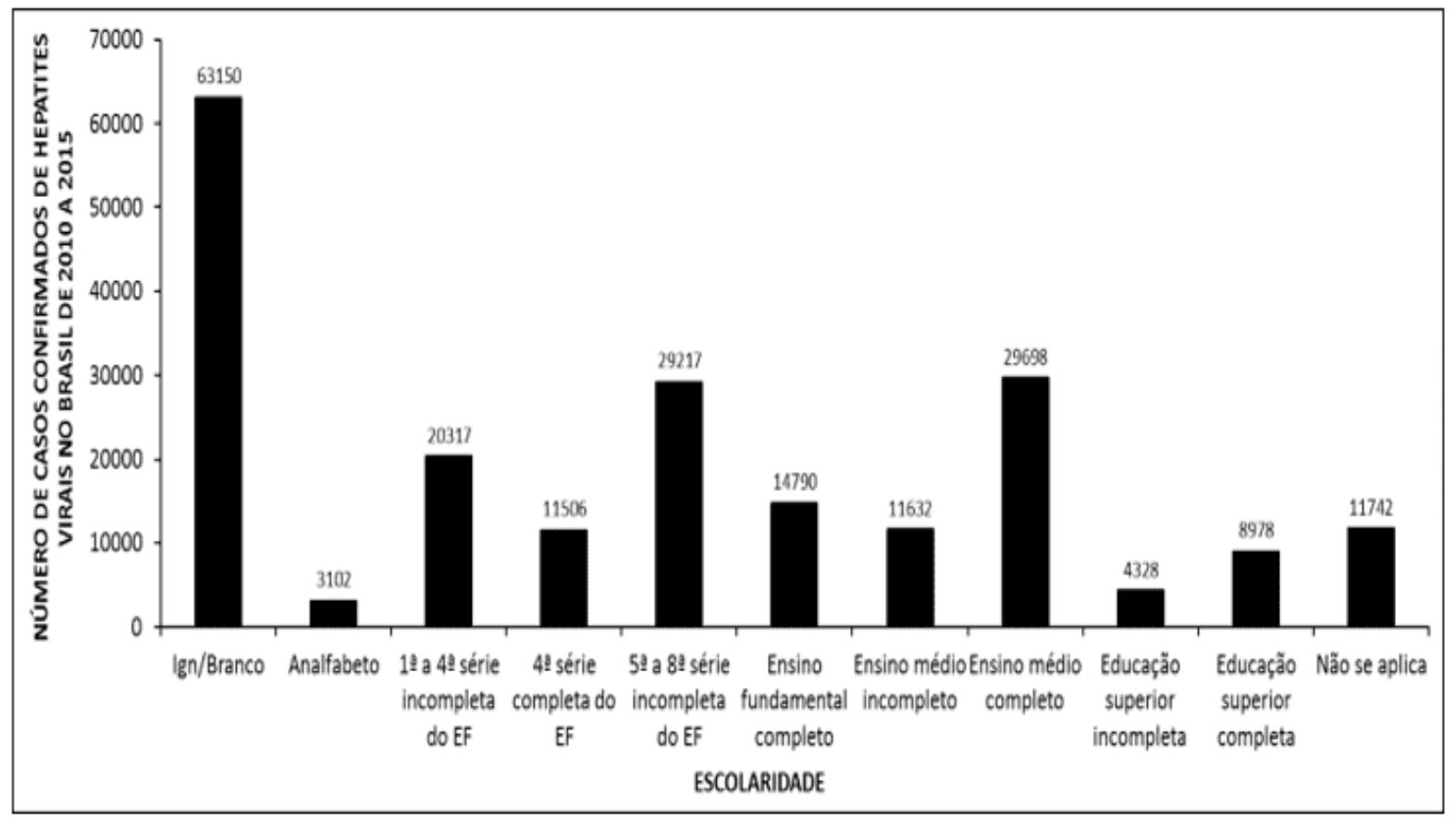

\section{DISCUSIÓN}

La hepatitis viral es un problema integral de salud pública en Brasil. Teniendo en cuenta varios factores, como la irregularidad de la distribución de los servicios de salud y la desigualdad concomitante de la tecnología de diagnóstico, además de la disparidad económica y social, es posible comprender algunas de las razones que están vinculadas al alto número de hepatitis en el país. Además de estos, el conocimiento inexacto sobre el número de personas infectadas y la insuficiente instrucción sobre los agentes etiológicos de la hepatitis viral y sus medios de transmisión también contribuyen negativamente a la dinámica del avance de la patología en Brasil (FERREIRA y SILVEIRA, 2004).

Entre los individuos infectados con los diversos virus causantes de hepatitis, la mayoría es hombre. Numerosos estudios indican que los hombres tienden a ejercer menos demanda de servicios médicos en general y, en vista de este hecho, sufren

RC: 67622

Disponible: https://www.nucleodoconhecimento.com.br/salud/hepatitis-viral 
más muertes por enfermedades crónicas (GOMES et al., 2007). Entre los principales grupos en riesgo de infección por el virus de la hepatitis, especialmente el VHB, se encuentran: profesionales de la salud, personas que consumen drogas intravenosas, pacientes de hemodiálisis, profesionales del sexo y personas homosexuales masculinas (FERREIRA y SILVEIRA, 2004).

A través de los datos del Boletín Epidemiológico de Hepatitis Viral 2015, es posible verificar los principales rangos de edad en los que predominan los casos de hepatitis. En el caso de la hepatitis $A$, la infección tiende a ocurrir principalmente entre los niños menores de 10 años de edad, y el pico está en el rango entre 5 y 6 años. En relación con la hepatitis $\mathrm{B}$, el pico de casos se produce en el rango de edad de 20 y 30 años. En hepatitis C, se observa que la tasa más alta de casos ocurre entre individuos de 40 a 60 años (BRASIL, 2015). Una observación importante es el aumento significativo $-97,7 \%$ - de la transmisión de la hepatitis A en varones, entre 20 y 39 años de edad, a través de medios sexuales, según el Boletín Epidemiológico de Hepatitis Viral 2018 (BRASIL, 2018a). La vía sexual de transmisión de la hepatitis C es objeto de debates, ya que, a diferencia del potencial reconocido de transmisibilidad sexual de la hepatitis $\mathrm{B}$, el VHC tiene una infectividad sexual que se produce de manera limitada y, por lo tanto, no está clasificada de hecho como ITS (Infección de Transmisión Sexual) (ALMEIDA y MARTINS, 2015).

En Brasil, entre 1999 y 2018, hubo 632.814 casos confirmados de hepatitis viral. De estos casos, el 36,8\% (233.027) están relacionados con la hepatitis $\mathrm{B}$, el $36,1 \%$ (228.695) con la hepatitis C, que representan la cifra más alta. La hepatitis A representa el $26,4 \%$ del total (167.108), además del $0,7 \%$ de la hepatitis $D(3.984)$, esta última es hepatitis con el menor número de notificaciones y una diferencia global, en números, de la otra. La hepatitis C, desde 2015, ha superado anualmente el número de hepatitis B en las tasas de incidencia (BRASIL, 2019). Un elemento a tener en cuenta es la coinfección con el virus de la inmunodeficiencia humana (VIH) y la hepatitis B (VHB) y C (VHC), ya que entre el $70 \%$ y el $90 \%$ de los pacientes infectados por el VIH tienen marcadores de infección por VHB (FARIAS et al, 2012)

$\mathrm{RC}: 67622$

Disponible: https://www.nucleodoconhecimento.com.br/salud/hepatitis-viral 
El diagnóstico clínico de hepatitis viral se produce a través de signos y síntomas presentados por el paciente, y las personas que tienen el virus puede presentar condiciones sintomáticas agudas, crónicas e incluso asintomáticas. En la hepatitis aguda, el paciente puede presentar malestar general, fatiga, náuseas, choluria (orina oscurecida), anorexia, ictericia y heces de color blanquecino. En el caso de una imagen de hepatitis crónica, a veces los individuos pueden ser asintomáticos, sin embargo, las afectaciones hepáticas pueden aparecer después de un cierto período, como cirrosis hepática, fibrosis hepática e incluso carcinoma hepatocelular (dependiendo de la evolución, otros órganos pueden verse comprometidos). El diagnóstico se produce principalmente en la fase crónica de la enfermedad (principalmente en hepatitis B y C). A nivel de laboratorio, es posible detectar marcadores para la hepatitis, y el contenido utilizado para este proceso son fluidos orales, sangre, suero o plasma del paciente infectado, a través de técnicas llamadas inmunoensayos. Estos procedimientos tienen como objetivo detectar el antígeno en sí o anticuerpos y hay diferentes tipos: ensayos inmunoenzimáticos, pruebas luminiscentes y rápidas. Además de estos, también hay pruebas moleculares, basadas en la reacción en cadena de la polimerasa (PCR) (BRASIL, 2018b y SBI, 2003)

La escolarización es uno de los factores que se tienen en cuenta epidemiológicamente para entender el impacto de la hepatitis en Brasil. En relación con los casos confirmados de hepatitis viral, se observa que una gran proporción de personas con escolaridad del quinto al octavo grado de la escuela primaria, y de 1999 a 2018, entre los hombres, de todos los casos confirmados, hubo 21.844 que corresponden a este perfil (inferior sólo a la categoría "ignorado", a través de datos del Epidemiológico Bulletinical de Hepatitis Viral 2019) (BRASIL, 2019).

RC: 67622

Disponible: https://www.nucleodoconhecimento.com.br/salud/hepatitis-viral 


\section{CONCLUSIONES}

La hepatitis representa un gran problema de salud pública en Brasil, y factores como la distribución desigual de los servicios de salud, las disparidades socioeconómicas y otros problemas contribuyen a este imbroglio.

De los infectados, una gran parte está compuesta por individuos varones, y la demanda más baja visible de servicios de salud es un factor importante para este hallazgo. Debido a esto es, tienden a sufrir más afectación crónica derivado del retraso en la búsqueda de un profesional de la salud. Los pacientes de hemodiálisis, los trabajadores sexuales y las personas que usan drogas inyectables son algunos de los principales grupos de riesgo para la infección viral por hepatitis. Además, se constató que, de 1999 a 2018, una gran proporción de casos confirmados de hepatitis (21.844 casos) correspondían a personas con escolarización incompleta desde el quinto al octavo grado de la escuela primaria.

La hepatitis B y C son las más comunes entre las hepatitis virales. En los últimos años, ha habido un aumento significativo (más del 90\%) transmisión sexual de la hepatitis B. La transmisión sexual de la hepatitis $C$ es una delicia, y su potencial de transmisibilidad sexual se considera limitado y, por lo tanto, no se considera una ITS.

Uno de los factores importantes y que contribuyen a la tasa de infección por el virus de la hepatitis es su coinfección por el $\mathrm{VIH}$. Alrededor del $70 \%$ al $90 \%$ de los pacientes seropositivos tienen marcadores de infección previa por VHB.

En el caso de la hepatitis viral, se tienen en cuenta los criterios clínicos y de laboratorio. Los signos y síntomas como ictericia, choluria, heces de color blanquecino, fatiga, malestar general, náuseas y otros pueden presentarse en el paciente con hepatitis. Sin embargo, también puede haber casos asintomáticos, que contribuyen al retraso del diagnóstico y a la consiguiente cronicidad de la enfermedad. Se deben realizar pruebas de laboratorio (inmunoensayo, pruebas

RC: 67622

Disponible: https://www.nucleodoconhecimento.com.br/salud/hepatitis-viral 
moleculares) para detectar marcadores y determinar el agente etiológico causante de la patología.

\section{REFERENCIAS}

ALMEIDA, C. S. C.; MARTINS, L. C. Soroepidemiologia do vírus da hepatite C em cônjuges de portadores desse vírus. Revista Paranaense de Medicina, v. 29, n.1, p. 11-16, 2015.

BRASIL. Ministério da Saúde. Portal da Saúde. PRENVENÇÃO-HEPATITES: HEPATITE D. Disponível em:< http://portalsaude.saude.gov.br/index.php/links-deinteresse/305-hepatites-virais/prevencao-hepatites/9124-hepatite-d> . 2014.

BRASIL. Ministério da Saúde. Portal da Saúde. PRENVENÇÃO-HEPATITES: HEPATITE B. Disponível em:<http://portalsaude.saude.gov.br/index.php/links-deinteresse/305-hepatites-virais/prevencao-hepatites/9130-hepatite-b > . 2014a.

BRASIL, 2015. Ministério da Saúde. Boletim Epidemiológico Hepatites virais. Ano IV, n. 01, 2015.

BRASIL, 2018a. Ministério da Saúde. Boletim Epidemiológico Hepatites Virais. V. 49, 2018.

BRASIL, 2018b. Ministério da saúde. Manual técnico para o diagnóstico das hepatites virais. 2018.

BRASIL, 2019. Ministério da Saúde. Boletim Epidemiológico Hepatites Virais. V.50, 2019.

FARIAS, N.; SOUZA, I.; COELHO, D. M.; OLIVEIRA, U. B.; BINELLI, C. A. Coinfecção pelos vírus das hepatites B ou C e da imunodeficiência adquirida: estudo exploratório no estado de São Paulo, Brasil, 2007 a 2010. Epidemiol. Serv. Saúde, v. 21 , n. 3, p. 475-486, 2012.

$\mathrm{RC}: 67622$

Disponible: https://www.nucleodoconhecimento.com.br/salud/hepatitis-viral 
FERREIRA, C. T.; SILVEIRA, T R. Hepatites virais: aspectos da epidemiologia e da prevenção. Rev. bras. epidemiol., v. 7, n. 4, p. 473-487, 2004 .

FERREIRA, A.R.; FAGUNDES, E.D.T.; QUEIROZ, T.C.N.; PIMENTA, J.R.; JÚNIOR, R.C. N.. Hepatites Virais A, B e C em crianças e adolescentes. Rev Med de Minas Gerais, (Supl 2): S46-S60, 2014.

FRANCISCO, P.M.S.B; DONALISIO, M.R; GABRIEL, F.J.O; BARROS, M.B.A. Vacinação contra hepatite $B$ em adolescentes residentes em Campinas, São Paulo, Brasil. REV BRAS EPIDEMIOL, 18(3): 552-567, JUL-SET 2015.

GOMES, R.; NASCIMENTO, E. F.; ARAÚJO, F. C. Por que os homens buscam menos os serviços de saúde do que as mulheres? As explicações de homens com baixa escolaridade e homens com ensino superior. Cad. Saúde Pública, v. 23, n.3, p. $565-574,2007$.

GUSMÃO, K.E et al. PERFIL CLÍNICO-EPIDEMIOLÓGICO DA HEPATITE C NA REGIÃO NORTE DO BRASIL ENTRE 2012 E 2015.Revistade Patologia do Tocantins, [S.I.], v. 4, n. 2, p. 41-45, jun. 2017.

LEITE, A.C.D. et al. . Avaliação das Internações Pela Hepatite Aguda B em Comparativo com a Aplicação de Doses da Vacina Contra Hbv, Na Região Norte. In: Luís Marcelo Aranha Camargo; Dionatas Ulises de Oliveira Meneguetti; Jader de Oliveira. (Org.). Atualidades em Medicina Tropical no Brasil: Educação em Saúde. 1ed.Rio Branco, Acre: Stricto Sensu Editora, 2020, p. 39-48.

MARGREITER, S. et al. Estudo de prevalêcia das hepatites virais b e c no município de palhoça-sc. Rev. Saíde Públ. Santa Cat., Florianópolis, v. 8, n. 2, p. 21-32, maio/ago. 2015.

MOCBEL, I.L.S.A. et al. CONHECIMENTO SOBRE HEPATITES A e E DOS ESTUDANTES DE UMA ESCOLA MUNICIPAL EM SANTARÉM - PA. Revista EM FOCO - Fundação Esperança/IESPES, [S.I.], v. 2, n. 24, p. 18-29, abr. 2016.

RC: 67622

Disponible: https://www.nucleodoconhecimento.com.br/salud/hepatitis-viral 
NUNES, H.M. et al. Soroprevalência da infecção pelos vírus das hepatites $A B, C, D$ e E em município da região oeste do Estado do Pará, Brasil. Rev. Pan-Amaz. Saúde, Ananindeua, v. 7, n. 1, p. 55-62, mar. 2016.

SBI (SOCIEDADE BRASILEIRA DE INFECTOLOGIA). Boletim terapêutico de HIV/Aids, DTS e Hepatites Virais. Ano I, n. 4, 2003.

SILVA, C.M; VIANNA, G.S.P; SOARES, M.C.P; AMARAL, I.S.A.; MOIA, L.J.M.P. AVALIAÇÃO DO HEMOGRAMA EM PACIENTES TRATADOS PARA HEPATITE C1. Revista Paraense de Medicina - V.28 (2) abril-junho 2014.

Artículo: Noviembre de 2020.

Aprobado: Noviembre, 2020.

$\mathrm{RC}: 67622$

Disponible: https://www.nucleodoconhecimento.com.br/salud/hepatitis-viral 